\title{
THE PROS AND CONS ABOUT THE DIGITAL RECORDING OF INTANGIBLE CULTURAL HERITAGE AND SOME STRATEGIES
}

\author{
Yang, Hong \\ The Academy of Arts \& Design, Tsinghua University, Beijing - yh678@tsinghua.edu.cn
}

KEY WORDS: Intangible Cultural Heritage, ICH, digital recording, documentaries, inheritors

\begin{abstract}
:
Intangible Cultural Heritage (referred to as ICH), whose fundamental nature different from the tangible cultural heritage is "Intangible", and the related physical presence of the heritage is not the core content. Digital means have irreplaceable advantages in recording intangible and dynamic ICH resources, while it also needs flexible and rigorous recording means as a support, thus striving to maximize resources recording and protection. This article will focus on the pros and cons about the digital recording of ICH, and preliminarily discuss some strategies used in the process of recording.
\end{abstract}

\section{OVERVIEW OF DIGITAL RECORDING OF ICH}

Record behaviour of Intangible Cultural Heritage can be traced back to the beginning of the advent of photography and video apparatus. Traditional performance arts, festivals and handicraft industry as important factors of different people's life and production, because of their representative, ornamental and recreational characteristics etc, often become the shooting object of early professional photographers. For example, the first film produced by Chinese is Beijing Opera fragments documentary called "Ding Jun Shan" (1905). Presently, some foreign institutions and organizations set up websites to share these early images and videos collections which contain photos, audio and video related with Intangible Cultural Heritage of human history and traditional culture. For example, the Norwich HEART's Digital Heritage Project in the east of England, digitally processing hundreds of the early archive films, aims to show the social history and tradition, these digital video resources present in the network, including the production process images of traditional agriculture, fisheries, animal husbandry and also local people's main entertainment etc. ${ }^{(1)}$ For another example, the Massachusetts Institute of Technology launched the MIT Visualizing Cultures Research in 2002, using new technology and visual materials unprecedentedly released ever to reconstruct the history for people. Lots of still images in the websites taking time and place as the coordinate, not only mainly reflect the important historical events and social backgrounds, but also reflect the traditional handicrafts and social life scenes in urban areas of China, Japan and other countries. ${ }^{(2)}$

In the last century, countries like France, Japan, South Korea and China all carried organized and large-scale record behaviours with cultural heritage being the object. For example, the French cultural heritage census began in 1960s, thus a census database of its survey results came into being with

${ }^{(1)}$ Digital Agency - Soak and ideas factory, Norwich HEART's Digital Heritage Project, UK http://www.archivealive.org/ (1 1 Mar. 2015)

(2) Massachusetts Institute of Technology, MIT Visualizing Cultures, USA http://ocw.mit.edu/ans7870/21f/21f.027/home/ (11 Mar. 2015) keyword index as the directory inquiries. It can be said that before the popularization of computer technology, record keeping mainly relies on editing and publishing numerous survey results. In this century, countries signed the UNESCO " Convention for the Safeguarding of Intangible Cultural Heritage ", which was an opportunity, coupled with the rapid popularity and development of digital technology, many countries' official and folk behaviours went into the flourishing stage of digital recording as the object of $\mathrm{ICH}$ through the field investigation, establishing archives and rescue protection. For example, while carrying our national ICH census, the government also launched the "Digital Chinese Intangible Cultural Heritage Conservation Project" to obtain the basic information and digital recording (including audio and video, etc) of all levels of ICH projects as well as to build a database. At the national level ICH digital capture standard into the pilot phase, currently completion four projects, such as Gaomi flutter gray pictures, Shanxi Opera, Anhui Hui-style traditional houses architectural and building skills, southern $\mathrm{Wu}$ songs. In addition, the "Chinese Folk Cultural Heritage Rescue Project" has established a "graphic information database of Chinese folk culture" with the help of social organizations; the collection and codification work of "Integration Annals of Chinese Folk Literature and Art" began in the 1980s, and now its full text has been completely digitalized.

Generally speaking, digital recording of ICH, with all kinds of ICH resources as recording objects, aims to generate digital resources by means of inputting, scanning, photography, transcription, image pickup and so on. It together with storing and sharing ICH digital resources constitutes the entire process of Intangible Cultural Heritage digital protection. The core of ICH is invisible but specific behaviours and habits, which makes it uniquely different from other heritage categories. Due to the invisible nature of $\mathrm{ICH}, \mathrm{ICH}$ recording is in urgent need, which provides places for digital technologies. So, what are the pros and cons about digital recording of ICH? What problems you might encounter in the generation process of ICH digital resources?

\section{THE PROS AND CONS ABOUT DIGITAL RECORDING OF ICH}




\subsection{To convert the "invisible" into "visible"}

With the help of powerful functions in auxiliary realization, modern digital technologies enable digital resources to have high ability of recording, presenting and creating, which to some extent has the invisible ICH projects to be visible. Before the ICH projects abnormally vary, defect or even disappear, they must be solidified in a visual and audible digital form, and become the core contents of the digital recording of ICH. For example, digital video recording of the ICH item "Li dress", launched by Hainan National Institute in March 2013, is the image data recording behaviour for the purpose of safeguarding heritage. ${ }^{(3)}$

\subsection{To achieve a high dynamic degree}

Although there are factors and carriers of substances, but ICH's value is not primarily manifested through physical form. ICH belongs to the category of human behaviour activities. Some need the help of action to display it, some need to be created and passed down through the skills. The performance and heritage of ICH require language and behaviour, is a dynamic process. In general, ICH items are a dynamic realized process, which requires taking digital means to record the complete process, the video and audio recording temporal and spatial evolution process has an irreplaceable advantages. It is also the reason that since the popularity of audio and video equipment, it has long been introduced to folklore fieldwork, oral history and other areas. For example, ICH traditional performance arts items, the main digital record media is audio and video, which requires the use of image pickup and audio devices completely and fidelity recording the whole picture and sound of the show process. Contemporary, digital audio and video devices can realize high-fidelity, high-definition audio and video, plus multi-camera shooting techniques, multimedia presentation technology, ICH, the degree of realization of the digital resources' dynamics is increasing. ${ }^{(4)}$ In recent years, some scholars have begun to specialize in the ICH imaging protection video recording is indeed the best means of meeting the needs of the dynamic nature of ICH.

\subsection{Digital recording having no guide to act}

However, there are also some drawbacks about digital recording of ICH at the present stage. Compared with material cultural heritage, digitization of ICH started much later. For example, in China cultural relics museum information system construction began in the 1980s; digital preservation and display have already developed for more than ten years, while ICH conservation as an emerging project, only has a dozen years of history. ${ }^{(5)}$ The relevant national standards of ICH digitization are still in the pilot phase, although there are many means to record still images and some others in the field of museums and libraries, which can still be used in digital preservation of ICH.

(3) Wang Hong Wei, Rong Wei Jun, 2013. Digital recording of Li Nationality costume, Hainan Daily

(4) Yang Hong, 2014, Research on the digitization of Intangible Cultural Heritage. Social Sciences Academic Press, Beijing, pp .57.

(5) Yang Hong, 2014, Research on the digitization of Intangible Cultural Heritage. Social Sciences Academic Press, Beijing, pp .10.
However, ICH is still in an exploratory stage , the greater using area of audio and video as well as the means of modern digital technology relatively less standards can be directly follow and learn from to the practice, targeted research needs to be strengthened.

\subsection{Video and audio being flawed in terms of full-sensory experience}

At the same time, we see that the digital recording of ICH was flawed in the whole sensory experience and other aspects. The intangibility of ICH is also reflected in the olfactory, taste, touch and emotional experience fields beyond visual and audio, which is hard to direct record and spread by digital recording and display. For example, to record the wine and vinegar's production techniques, is an indispensable step for each channel special from assail the nostrils smell; to record the north and south different characteristics of customs and festivals, only to shoot the ceremony itself, can't record and convey one of the traditional beliefs and simple emotion embedded in. Thus when we create these ICH digital resources which are closely related to special sensory experience, we should focus on the indirect record about special sensory experience, bridging some short board which is also difficult to achieve by digital technologies; In the stage of display and spread, we can also introduce the virtual interactive technology, etc., to provide more comprehensive and real sensory experience.

\subsection{Pros and cons of virtual reproduction}

To some extent, digital resources are non-tangible resources which exist in a virtual computer environment, with intangible qualities and limitations. To capture and preserve the core content of the intangible heritage items is not that easy; it is a must to properly understand of the concept and value judgments about ICH. For example, ICH items within the category of traditional festive ceremony, whose digital object is a multidimensional "cultural space" running through time and space, can be recorded by new digital multimedia technologies, in addition to audio and video recording, such as 3D animation and virtual reality under the circumstances of enough capital and technology. However, in the digital environment, it "created" the manifestations, display processes and the exist environment and others of ICH items, but also contrary to the authenticity which is the premise of archived protection, the more reliable approach is to make "virtual reality" based on the real world and the true overall recording, with full respect for the existence of the heritage form and the true state of the environment. On the sharing and dissemination of $\mathrm{ICH}$, we should also see the introduction of new technology to achieve ultra-realistic and holographic digital resources of ICH access experience represents the direction of future development, will gradually become an important supplementary protection and inheritance behaviour means.

\section{STRATEGIES FOR DIGITAL RECORDING OF ICH}

\subsection{To note the difference between documentary and video} archives 
Contemporary documentaries with the theme of ICH suit the needs of modern communication, but they are somewhat different from the ICH video recordings with the purposes of recording or archive. In fact, their records have different purposes and this directly affects the focus and integrity of recorded images; secondly, there is distinction between simple objective record and thoughtful objective record. Documentaries usually have their implicit purposive, passing the personal thoughts and feelings from producers, screenwriters, directors and videographers. Sometimes this kind of subjective intent and emotion will control the perspective and content, affect the integrity and authenticity of the records.

\subsection{To focus on the selection of digital objects, without blind digitization}

Because of the large investment of digital preservation, thus taking the rheology of ICH into account, we should do well to plan and judge before the implementation of digital protection. We must rely on existing research results, items' expert demonstration and other means to control the rheological in advance of specific projects, to confirm the source of inheritance; thus the main target of digital recording for locating the source of heritage, focusing on the essence of the recording project, keep the most original items' inheritance patterns.

Secondly, the object of ICH digital recording is traditional ICH items, rather than the contemporary art using ICH elements. When implementing digital recording, we must strictly distinguish traditional ICH and contemporary art products, strictly control recording objects and scopes; to fully comply with the original appearance to digitize records, eliminate "staged "," deductive "behaviour for the purpose of the digital effects and changing the items' original presentation form. For example, when shooting dragon and lion dance, stilt, lift Court and other items, to get beautiful and neat recording screen, any artificial "packaging" for performers, wear uniforms, or even leave the daily performance spaces, organized into "better condition " Grand Theatre to perform and shoot, are undesirable behaviour contrary to the principles of objective record.

\subsection{To carry the digital recording around ICH inheritors}

Inheritors are the critical lifeblood of the projects' existence and living heritage, and also the core of heritages' recording and protection. Conserving actions should take full account of inheritors' complicated and worrisome survival status quo in contemporary, both focusing on recording inheritors and the need to avoid excessive interference to their daily trajectory. Because of the special and close relationship between ICH items and inheritors, that we carrying out digital recording, we must fully realize the necessity to carry out around the inheritors, comprehensive and stereoscopic saved the inheritors' information data. For example, traditional arts and crafts category and some traditional production and life knowledge and skills category of ICH items, in the use of camera equipment to shoot craft production process, the more through record oral histories and other ways, preserved the inheritors' understanding of the process.

Specifically, (a) try to avoid an impact on the normal heritage behaviour, absolutely avoid direct and indirect damage to the inheritors' livelihoods. (b) To improve the intellectual property protection and privacy protection program, by strengthening the safety management of the recorded data, setting the core knowledge and skills virtual storage area in the database, and setting strict access control. Under the premise of protecting the inheritors' rights and data security, maximize the collection of core intelligence and skills from ICH items. (c) use of digital Internet technology, by building a network communications platform, interactive platform, advisory services platform and other channels, to dig and reflect the plight of inheritors and their heritage behaviours, to promote information exchange and information support in the conservation and heritage, to promote implementation of various protective measures promptly. For example, India's traditional costumes Chanderi "sari" weaving skills ushered in a new opportunity for heritage and conservation, just because of the digital Internet technology. This project called Chanderiyaan launch e-commerce portal, providing market and business platform to build bridges and maintenance services for the traditional handicraft, makes the weaving families' livelihoods greatly improved while the local average monthly income does not exceed Rs 3,000. ${ }^{(6)}$ (4) Change the digitized results into a powerful tool for inheritors' Rights and Interests. By transparent release ICH items' owners' information, intellectual property information etc., promote ICH intellectual property rights and ownership protection.

\subsection{To carefully select the digital preservation format and medium}

In the early stage of digital recording, we must confirm that the first position of the data security. First of all, to ensure the physical medium for data storage (such as magnetic tape, tape, CD-ROM, hard disk and so on) and the digital documents' physical security and long-term availability. For example, the China Record Corp timely transcript and save the precious mica tape and old albums through the digital mode, including Original Soundtrack of the famous Peking Opera and other traditional operas since the Five Four. ${ }^{(7)}$

\subsection{To strengthen the combination with related knowledge and technologies}

Digital recording of ICH requires not only ICH protection theory, the relevant digital technology, but also assisted audio and video technology, intellectual property practical knowledge, stage lighting knowledge and other fields of knowledge and technology. For example, oral history records should be kept of respondents and projects' core intelligence, to save the field workers' views and thinking etc. guiding spirit on the project, show the core theme of the project and the core point of view from the respondents through the audio or video recording; at the same time we should pay attention to some technical problems in the implementation phase of the digital recording, such as lighting conditions during video, the requirements of the voice when recording the audio etc. For example, in the digital shooting of the traditional process, in addition to shooting content and technology requirements, the most important things are through the core technology shooting confidentiality agreement and a series of supporting regulations, to ensure that the business secrets and intellectual property rights are not infringed. Another example, shooting the traditional performing arts projects, to understand the stage camera and lighting, multi camera video, the voice of the same

(6) Chanderiyaan project, Chanderiyaan Web Site, India http://chanderiyaan.net/ (11 Mar. 2015)

(7) Gong Zheng, 2012. The massive historical acoustic digital preservation, Beijing Daily 
period recording and other aspects of the technical requirements; while filming a large festival is more complex, must grasp the multi camera recording, filming, documentary film, shot the technical points, but also to understand the nature light and auxiliary light, composition and other aspects of the practical knowledge.

All in all, when we carry digital recording of $\mathrm{ICH}$, we should follow the following four basic principles: (a) performance, manufacture, development and process carried out are the essence of Intangible Cultural Heritage, and the dynamic process converting the "invisible" to "visible" is the core content of digital recording; (b) the heritage-related things, like manufactured goods, raw materials, tools, places, props, costumes, text, etc., need to be recorded digitally and completely, however, they are not the core of ICH preservation and digital recording; (c) because of the complexity and variety of ICH resources, digital process is complicated and diverse. Different categories need different digital means and also have identical realization degree; (d) the ICH inheritors are the key lifeline for items' existence and living heritage, and also the core of preservation and protection, therefore we should carry out the digital recording flexibly focusing on the inheritors. Certainly, the related background information about practitioners and inheritance is also important content must be recorded.

\section{CONCLUSIONS}

Recording intangible and dynamic Intangible Cultural Heritage resources, digital means have their irreplaceable advantages, while there is also a need for flexible yet rigorous recording means as a support, striving to maximize resources recording and protection. However, the greater using area of audio and video as well as the means of modern digital technology are still in the exploratory stage, relatively less standards can be directly follow and learn from to the practice, targeted research needs to be strengthened. Thus, when we create some kinds of ICH digital resources closely related to special sensory experiences, like smell, taste and feeling, we should focus on the indirect record about special sensory experience, bridging some short board which is also difficult to achieve by digital technologies. However, in the digital environment, it "created" the manifestations, display processes and the existed environment and others of ICH items, but also contrary to the authenticity which is the premise of archived protection. Therefore, in the practice of ICH digital recording, we must follow these basic principles: (A) to note the difference between documentary and video archives; (B) to focus on the selection of digital objects, without blind digitization; (C) to carry the digital recording around ICH inheritors; (D) to carefully select the digital preservation format and medium; (E) to strengthen the combination with related knowledge and technologies.

\section{REFERENCES}

Digital Agency - Soak and ideas factory, Norwich HEART's Digital Heritage Project, UK http://www.archivealive.org/ (11 Mar. 2015)

Massachusetts Institute of Technology, MIT Visualizing Cultures, USA http://ocw.mit.edu/ans7870/21f/21f.027/home/ (11 Mar. 2015)
Wang Hong Wei, Rong Wei Jun, 2013. Digital recording of Li Nationality costume, Hainan Daily

Yang Hong, 2014, Research on the digitization of Intangible Cultural Heritage. Social Sciences Academic Press, Beijing, pp .10-57.

Chanderiyaan project, Chanderiyaan Web Site, India http://chanderiyaan.net/ (11 Mar. 2015)

Gong Zheng, 2012. The massive historical acoustic digital preservation, Beijing Daily 